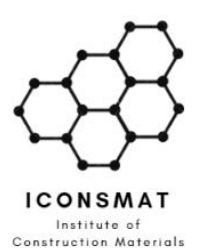

Content list available at ICONSMAT

Journal of Construction Materials

Journal homepage: www.iconsmat.com.au/publication
Article history:

Received 5 September 2020

Received in revised form

7 September 2020

Accepted 8 September 2020

Available online

2 October 2020

\title{
A brief critical view on the carbon-conditioning of recycled aggregate using pressure chamber
}

\author{
Farid Sartipi ${ }^{1 *}$ \\ 1* Corresponding author: E: farid.sartipi@iconsmat.com.au; Institute of Construction Materials
}

\begin{abstract}
$\mathrm{CO}_{2}$ Concrete as an environmental material had attracted the public view for many years. Several methods had been proposed for entrapping $\mathrm{CO}_{2}$ gas in concrete some of them targeting cement paste as the reactant with the $\mathrm{CO}_{2}$ gas and the other methods consider aggregate as the reactant. The common purpose of all, is to, first, reduce the impact of greenhouse gas emissions via the means of $\mathrm{CO}_{2}$ gas consumption, and second, to increase the mechanical properties of concrete by accelerating the formation of calcium carbonate crystals. Seeking to achieve a successful wide scale commercialization, it is important to address the flawed aspects of a concept. This paper projects a critical point of view on some basic flawed assumptions taken as facts, in the conceptualization of carbon-conditioning of recycled aggregate.
\end{abstract}

DOI: 10.36756/JCM.v2.1.4 (C2020 Institute of Construction Materials

\section{Keywords}

$\mathrm{CO}_{2}$ Concrete; Chemical absorption; Recycled aggregate 


\section{Introduction}

With an increasing attention to the environmental impact of construction, scientist and the broad community of construction practitioners are making attempts to reduce the level of greenhouse gas emissions. Concrete as the most widely used material after water globally accounts for the largest portion of the $\mathrm{CO}_{2}$ emission. Two main ingredients of concrete, being cement and aggregate, have the highest level of human exploitation of natural resources. And in order to reduce these harmful effects, the use of supplementary cementitious materials and recycled aggregate had become popular. Nevertheless, the environmental impact of this human made rock, concrete, is still considerably high. Governments across the globe are investing significantly on the new environmental technologies to lower the environmental impact of construction even further down. One of the emerging technologies in this area is called $\mathrm{CO}_{2}$ Concrete.

\section{Carbonation techniques}

There are three major $\mathrm{CO}_{2}$ concrete technologies proposed so far, each with their own unique procedures. Kou et al. [1] uses a vacuum/pressure chamber for the carbonation of recycled aggregate. In the procedure introduced by Kou et al., the chamber is vacuumed to -50 KPa before the $\mathrm{CO}_{2}$ injection. The $\mathrm{CO}_{2}$ pressure in the chamber is controlled by a regulator at $10 \mathrm{KPa}$ with different carbonation period. In order to avoid the exposure of aggregates to humidity (which is claimed to be disruptive to the carbonation reaction) a silica gel is placed at the bottom of the chamber underneath the aggregates. The schematic view of this methods is shown in figure 1 below.

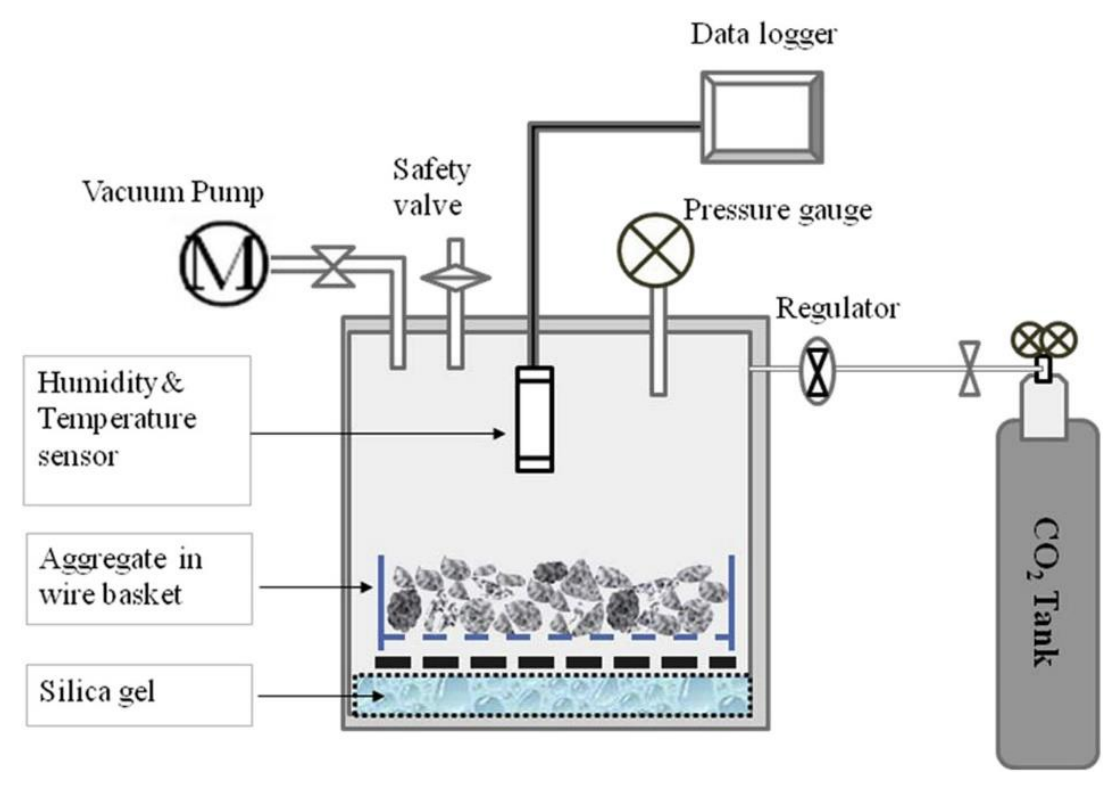

Figure 1 Schematic of $\mathrm{CO}_{2}$ curing experiment by Kou et al. [1]

In another method proposed by Bao Jian et al. [2] hardened concrete blocks are placed in a tube where the $\mathrm{CO}_{2}$ flows through. The tube has a diameter of $15 \mathrm{~cm}$ and a length of $40 \mathrm{~cm}$. The flow rate is controlled by a regulator and ranges from $0.2-10 \mathrm{~L} / \mathrm{min}$ depending on the experimental setting. The gas 
outlet is connected to a limewater container to absorb the surplus $\mathrm{CO}_{2}$. The figure 2 below illustrates the procedure in this method.

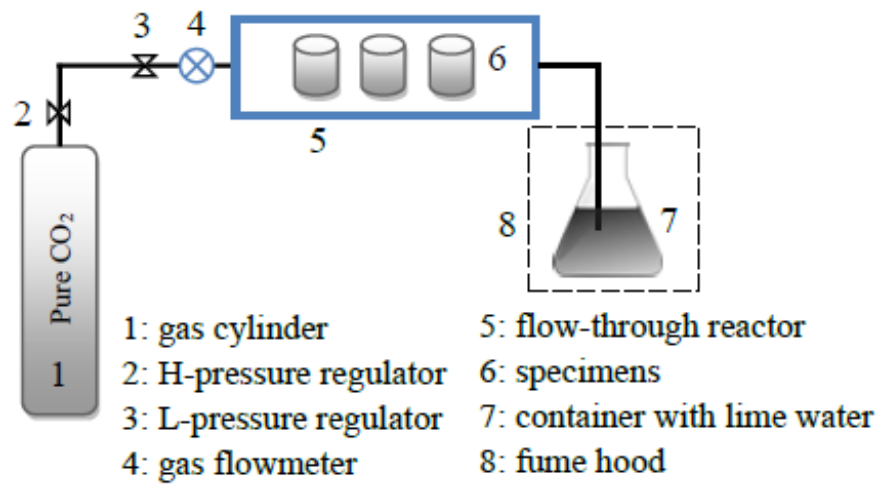

Figure 2 Flow-through $\mathrm{CO}_{2}$ curing method proposed by Bao Jian et al. [2]

Butera et al. [3] introduces the similar procedure to Kou et al. except in his procedure, aggregates are exposed to a higher $\mathrm{CO} 2$ pressure. Vacuuming the chamber and the presence of silica gel is also another major difference between these two methods. Figure 3 below shows the procedure introduced by Butera et al.

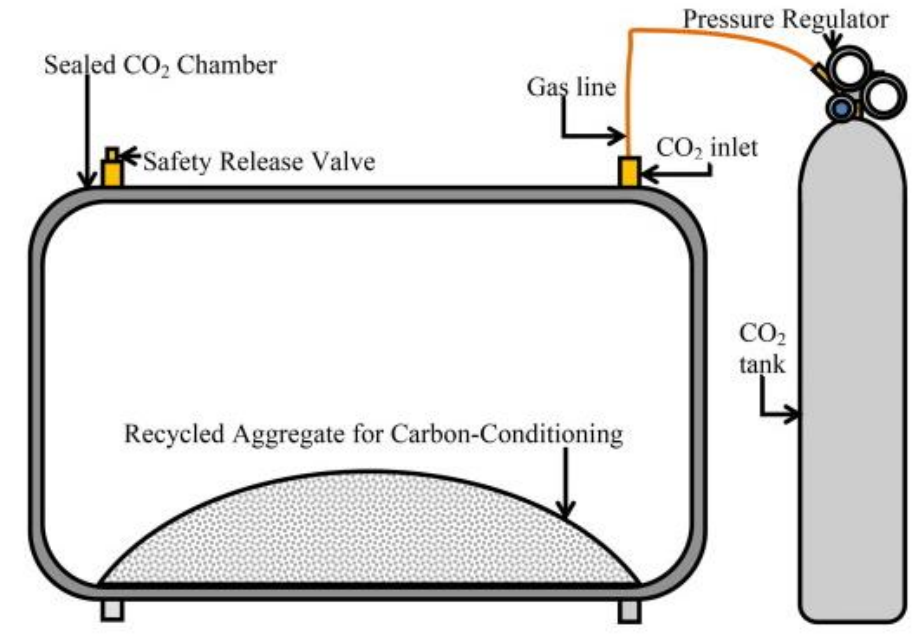

Figure 3 Schematics of carbon conditioning method proposed by Butera et al. [4] 


\section{Carbonation reaction}

Carbonation process is a complex process of mass transfer and chemical reactions. Commonwealth Science and Industrial Research Organization (CSIRO) outlines that the $\mathrm{CO}_{2}$ mineral carbonation is compromised of three distinctive steps respectively: leaching of solid matrix; $\mathrm{CO} 2$ dissolution into solution; carbonate precipitation. The reaction demands stirring as the efficiency requirement [5]. The chemical reaction is as followed:

$\mathrm{Ca}(\mathrm{OH})_{2(\mathrm{aq})}+\mathrm{CO}_{2} \rightarrow \mathrm{CaCO}_{3}+\mathrm{H}_{2} \mathrm{O}$

This reaction is zeroth order with respect to carbon dioxide concentration at ambient temperature [6]. A zero-order reaction is a chemical reaction wherein the rate does not vary with the increase or decrease in the concentration of the reactants. The rate of these reactions is always equal to the rate constant of the specific reaction.

The kinetics of the reaction requires an activation energy of $145 \mathrm{~kJ} / \mathrm{mol}$. Furthermore, this reaction occurs at the temperature of above $500^{\circ} \mathrm{C}[6-10] . \mathrm{CO}_{2}$ bond dissociation energy is reportedly given as $+532.2 \mathrm{~kJ} / \mathrm{mol}$ for a single oxygen and carbon bond in a $\mathrm{CO}_{2}$ molecule [11].

\section{Critical view}

\section{From the chemistry}

Referring to the kinetics of the carbonation reaction, none of the $\mathrm{CO}_{2}$ Concrete technologies mentioned before satisfies the conditions required for the reaction to occur. The so-called carbon-conditioning proposed by Butera et al. occurred at the ambient temperature with the varying pressure. Pressure variance in gaseous materials is equivalent to the change in the concentration of the $\mathrm{CO}_{2}$. Whereas, carbonation is intrinsically a zeroth order reaction at the ambient temperature i.e. change of pressure does not influence the rate of reaction at ambient temperature. Furthermore, $\mathrm{CO}_{2}$ covalent bond energy is fairly high. This molecule has a stable structure. At the exposure of this gas to the crystalline rocks the possibility of reaction is close to zero.

A negligible 3-10\% increase in the compressive strength was reported in the literature and correlated with the formation of calcium carbonate crystals as a result of carbon-conditioning recycled aggregate [3]. Considering the schematics of figure 3 and the presence of moisture and pressure in the chamber, it is highly possible that formation of carbonic acid causes an slight acid treatment of recycled aggregate which enhances the properties of ITZ zone, unless human errors are neglected.

\section{Petrography, scanning, and X-ray diffraction}

This section is based on the (wrong) assumption of the occurrence of the carbonation reaction.

A recently published paper by Tam et al. [12] states the petrographic analysis shows that aggregates are completely carbonated. A complete carbonation means that all reactants of the carbonation reaction above are consumed and the product is a white substance known as calcium carbonate. Whereas, in reality, there has been no changes in color observed after the so-called carbonation of recycled aggregate. Even in an ideal condition for the formation of calcium carbonates, the growth of solid product islands occurs on the surface of grain or pore [13] and not in the core of the aggregate which is emphasized in the pictures reported in the same article. The reported pictures in the article shows a bright yellow colour even at the depth of the aggregate that are apparently digitally modified 
(figure 4). It is more likely that the yellow colour intensity of the pictures had been modified by a software as in one plot cement reflects the yellow spectrum after the colour adjustment and in another plot, cement reflects a darker spectrum after the yellow colour intensity had been dimmed in the software.

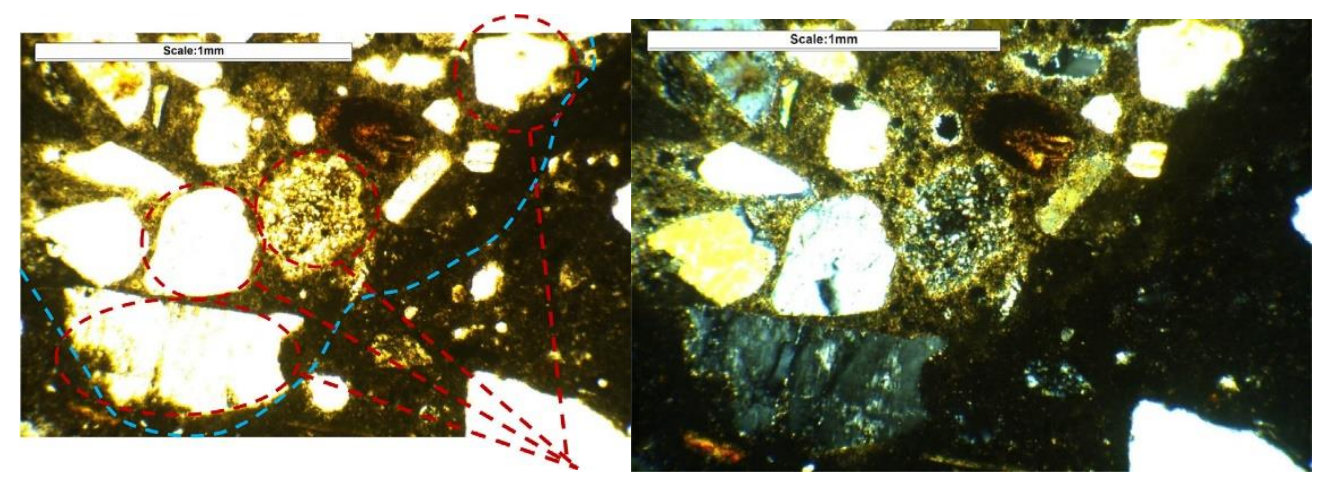

Figure 4 Petrographic results of so-called carbon-conditioning

There are two popular models for a general gas-solid reaction namely shrinking-core model and shrinking-pore model. The idea in both of these models is that the reactant material will be covered deep in the solid products as the reaction proceeds $[14,15]$.

The same study, in the results of x-ray diffraction indicates that crushed cement mortar has peak calcium carbonate content of 4 times higher than recycled aggregate which is not a new finding. Hydrated cement has a high portion of calcium carbonate regardless of the mixing method. Thus, the comparison is invalid.

\section{Conclusion}

Considering the kinetics of carbonation reaction which results in the formation of calcium carbonate crystals, the formerly proposed methods of carbon conditioning of recycled aggregate are invalid. There are major assumptions that are neglected in the conceptualization of the so-called $\mathrm{CO}_{2}$ concrete using pressure chamber. First, the activation temperature for solid-gas reaction of calcium hydroxide and $\mathrm{CO}_{2}$ is above $500^{\circ} \mathrm{C}$. Cement kiln calcination, for example, occurs at the temperature of $900^{\circ} \mathrm{C}$. Second, the microstructure analysis presented in one of the articles does not imply the shrinking-pore model of solid-gas reaction. Third, carbonation is intrinsically a zeroth order reaction which means that the rate of reaction is independent from the concentration of the reactants i.e. change in the pressure inside the chamber does not have any effect on the growth of calcium carbonate.

Overall, it is not a scientific statement to label the corresponding phenomena as carbonation reaction. Carbonation reaction does not occur in the proposed method. The most possible reaction is the formation of carbonic acid at the exposure of moisture to carbon dioxide which can slightly accelerate the acid treatment.

\section{Conflict of interest}

The author declares that, to the best of knowledge, there is no potential for a future conflict as all participants are keen on upgrading the current $\mathrm{CO}_{2}$ concrete technology. 


\section{References}

[1] S.-C. Kou, B.-j. Zhan, and C.-S. Poon, "Use of a CO2 curing step to improve the properties of concrete prepared with recycled aggregates," Cement and Concrete Composites, vol. 45, pp. 22-28, 2014.

[2] B. Zhan, C. Poon, and C. Shi, "Properties of Cement-based Construction Materials Prepared with Construction Waste and CO2 Curing," in The 14th Internationa I Congress on the Chemistry of Cement, 2015.

[3] V. W. Y. Tam, A. Butera, and K. N. Le, "Carbon-conditioned recycled aggregates in concrete production," Journal of cleaner Production, 2016.

[4] V. W. Tam, A. Butera, K. N. Le, and W. Li, "Utilising CO2 technologies for recycled aggregate concrete: A critical review," Construction and Building Materials, vol. 250, p. 118903, 2020.

[5] F. Pacheco-Torgal, C. Shi, and A. Palomo, Carbon dioxide sequestration in cementitious construction materials. Woodhead Publishing, 2018.

[6] K. Van Balen, "Carbonation reaction of lime, kinetics at ambient temperature," Cement and concrete research, vol. 35, no. 4, pp. 647-657, 2005.

[7] D. K. Lee, "An apparent kinetic model for the carbonation of calcium oxide by carbon dioxide," Chemical Engineering Journal, vol. 100, no. 1-3, pp. 71-77, 2004.

[8] W. Ashraf and J. Olek, "Carbonation activated binders from pure calcium silicates: Reaction kinetics and performance controlling factors," Cement and Concrete Composites, vol. 93, pp. 85-98, 2018.

[9] M. Ramezani, P. Tremain, E. Doroodchi, and B. Moghtaderi, "Determination of carbonation/calcination reaction kinetics of a limestone sorbent in low $\mathrm{CO} 2$ partial pressures using TGA experiments," Energy Procedia, vol. 114, pp. 259-270, 2017.

[10] V. Nikulshina, M. Galvez, and A. Steinfeld, "Kinetic analysis of the carbonation reactions for the capture of $\mathrm{CO} 2$ from air via the $\mathrm{Ca}(\mathrm{OH}) 2-\mathrm{CaCO} 3-\mathrm{CaO}$ solar thermochemical cycle," Chemical Engineering Journal, vol. 129, no. 1-3, pp. 75-83, 2007.

[11] B. d. Darwent, "Bond dissociation energies in simple molecules," National Standard Reference Data System, 1970.

[12] V. W. Tam, A. Butera, and K. N. Le, "Microstructure and chemical properties for CO2 concrete," Construction and Building Materials, vol. 262, p. 120584, 2020.

[13] Z. Li, "General rate equation theory for gas-solid reaction kinetics and its application to $\mathrm{CaO}$ carbonation," Chemical Engineering Science, vol. 227, p. 115902, 2020.

[14] S. Bhatia and D. Perlmutter, "Effect of the product layer on the kinetics of the CO2-lime reaction," AlChE Journal, vol. 29, no. 1, pp. 79-86, 1983.

[15] G. Grasa, R. Murillo, M. Alonso, and J. C. Abanades, "Application of the random pore model to the carbonation cyclic reaction," AIChE journal, vol. 55, no. 5, pp. 1246-1255, 2009. 